\title{
Corrigendum: A gradient of Bmp7 specifies the tonotopic axis in the developing inner ear
}

Zoë F. Mann, Benjamin R. Thiede, Weise Chang, Jung-Bum Shin, Helen L. May-Simera, Michael Lovett, Jeffrey T. Corwin \& Matthew W. Kelley

Nature Communications 5:3839 doi: 10.1038/ncomms4839 (2014); Published 20 May 2014; Updated 1 Aug 2014

In this Article, several graphs in Fig. 2 have an incorrect label underneath the last data point; 'E14' in Fig. 2b-d should have been 'P14'. The correct version of Fig. 2 appears below. In addition, we omitted to properly cite the related paper by Thiede et al. in the Discussion section, whose details are as follows:

Thiede, B. R. et al. Retinoic acid signalling regulates the development of tonotopically patterned hair cells in the chicken cochlea. Nat. Commun. 5, 3840 (2014). 
a

RNA-seq data from E6.5 chick BP

\begin{tabular}{|l|r|r|}
\hline & Proximal & Distal \\
\hline Bmp7 & 572 & 1,144 \\
\hline Follistatin-like 1 & 1,482 & 821 \\
\hline Follistatin-like 4 & 376 & 128 \\
\hline Chordin-like 1 & 1,386 & 697 \\
\hline Twisted gastrulation & 1,028 & 708 \\
\hline
\end{tabular}

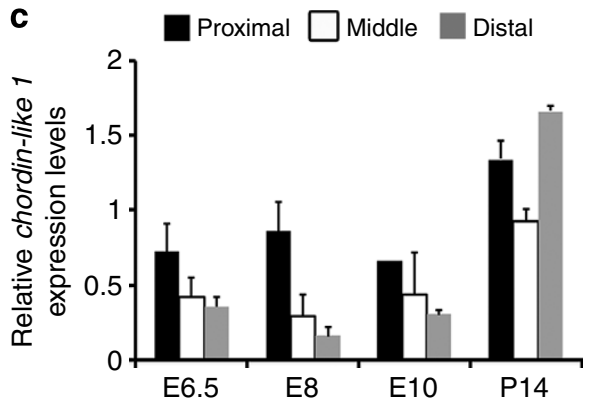

b

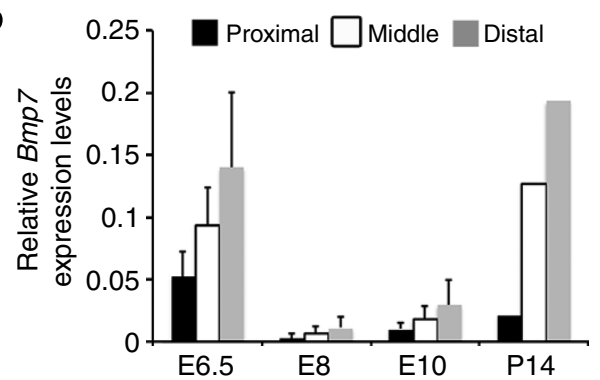

d

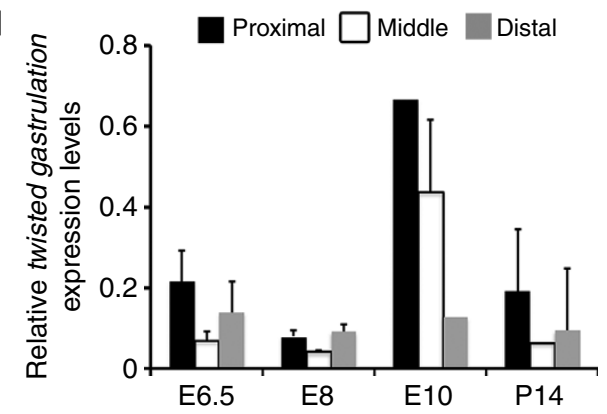

e
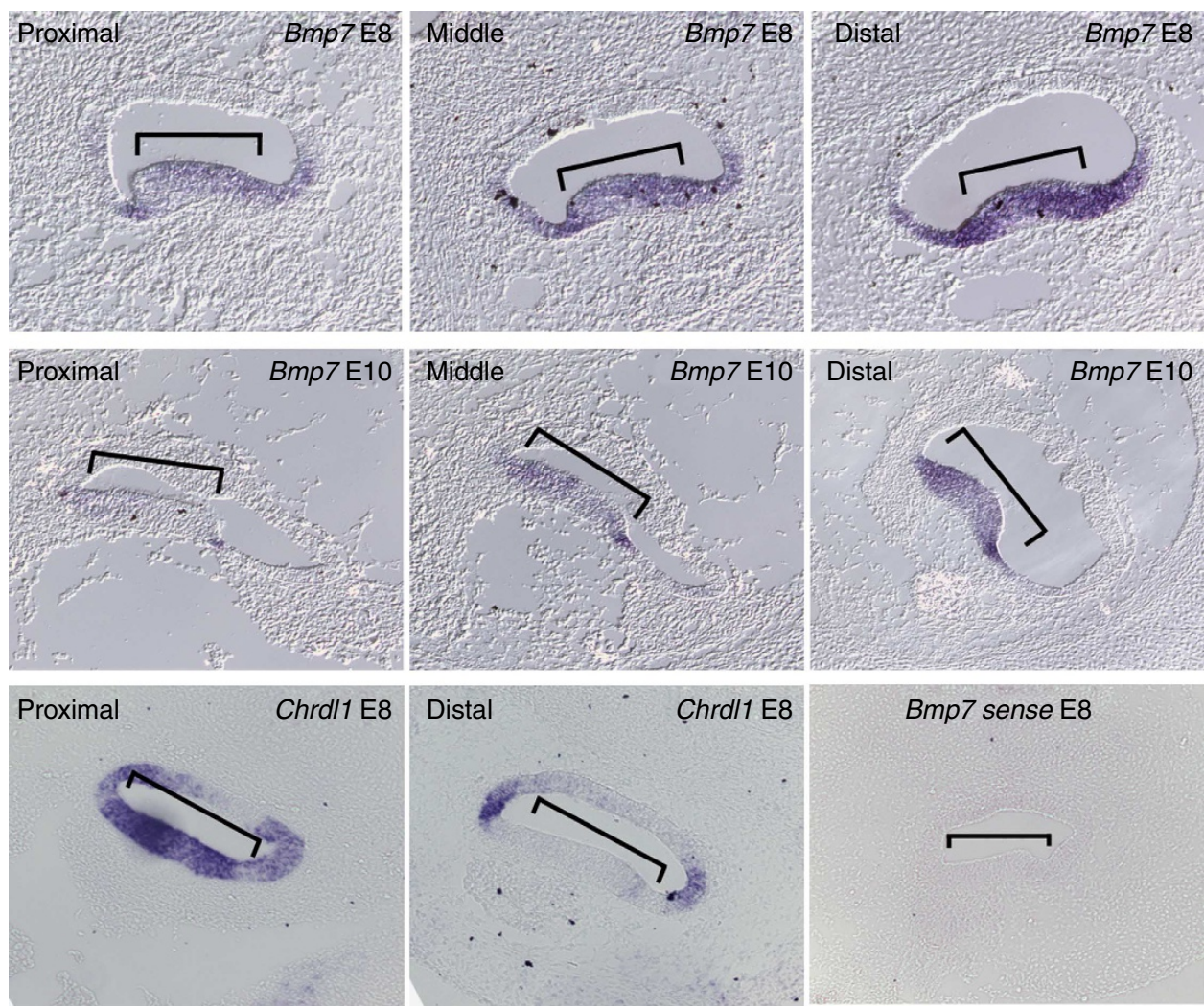

Bmp7 sense E8

Figure 2 